\title{
Recontextualizing social practices and globalization: Multimodal metaphor and fictional storytelling in printed and internet ads
}

\section{Recontextualizando práticas sociais e globalização: metáfora multimodal e narrativa ficcional em anúncios comerciais impressos e} na internet

\author{
Laura Hidalgo Downing* \\ Universidad Autónoma de Madrid \\ Madri / Espanha \\ Blanca Kraljevic Mujic** \\ Universidad Rey Juan Carlos \\ Madri / Espanha
}

\begin{abstract}
This article presents a study of ongoing global and local changing practices by exploring the interaction between multimodal metaphor and narrative in advertising discourse. Thus, we make use of Conceptual Metaphor Theory (CMT) and Conceptual Integration Theory to compare how social changes and continuities are represented and re-contextualized in advertising discourse, across time, genres and cultures. Changes in time and across genres are addressed through the analysis of printed ads from 2000-2002 and internet ads from 2001-2009. Second, we compare the interaction between TRANSFORMATION and MAGIC metaphors and storytelling frames in both genres and periods. Finally, we pay particular attention to the variation in a global brand campaign (CocaCola) in three different cultures, thus revealing competing changes in global and local social practices.
\end{abstract}

KEYWORDS: multimodal metaphor; advertising; narrative; sociocultural variation.

\footnotetext{
* laura.hidalgo@uam.es

** blanca.kraljevic@urjc.es
} 
RESUMO: Este trabalho apresenta um estudo de práticas aplicadas em nível local e global ao explorar a interação entre metáfora multimodal e narrativa no discurso publicitário. Utilizou-se a Teoria da Metáfora Conceitual (TMC) e a Teoria da Integração Conceitual, a fim de comparar como mudanças sociais e seus prolongamentos são representados e recontextualizados no discurso publicitário por meio do tempo, gêneros e culturas. Alterações no tempo e nos gêneros são abordadas por meio de análises de propagandas impressas de 2000 a 2002 e de anúncios na Internet no período de 2001 a 2009. Em segundo lugar, comparamos a interação entre metáforas de TRANSFORMAÇĀO e MÁGICA e frames de narrativas em ambos os gêneros e períodos. Finalmente, dá-se atenção especial à variação de uma campanha de uma marca global (CocaCola) em três culturas distintas, revelando mudanças competitivas em práticas sociais globais e locais.

PALAVRAS-CHAVE: metáfora multimodal; publicidade; narrativa; variação sociocultural.

\section{Introduction}

The study of metaphor has undergone numerous changes since Cognitive Linguists pointed out the prevalence of metaphor as a tool for thought and action in our everyday experience (LAKOFF \& JOHNSON, 1980; GIBBS, 1994). In the last decade, there has been an interest in exploring new dimensions of the use of metaphor in actual discourse, as well as of the communicative and ideological implications within specific social and cultural contexts (See also Cameron and Low, 1999; Charteris-Black, 2004; Gibbs, 1999; Kövecses, 2002, 2005, 2010; Mussolf \& Zinken, 2009; Semino, 2008). Additionally, special attention has been paid to the study of multimodal metaphor, that is, metaphor which involves the complementary or simultaneous cueing of the domains in different modes (verbal, visual, aural, gestural) (see also FORCEVILLE \& URIOS-APARISI, 2009a; HIDALGO-DOWNING \& KRALJEVIC MUJIC, 2013). Furthermore, recent contributions to the study of innovative and creative metaphors have been provided by Conceptual Integration Theory (CI), or Blending Theory, by providing a framework which allows greater flexibility for the study of complex creative metaphors (FAUCONNIER AND TURNER, 2002; DANCYGIER, 2005). This article is situated within this tradition of the study of metaphor in discourse. Our motivations for the present study are grounded on the following observations:

- There is a current need to approach the study of the interaction between metaphor, metonymy, and narrative in non-fictional genres, such as advertising. 
- Creative fictionality is a pervasive form of narrative to make sense of meanings grounded on socio-cultural practices.

- Advertising is an interesting hybrid genre for the study of the often implicit evocation of cultural and shared narrative fictions, which may have ideological implications.

Our main objectives are to explore:

- The nature of the interaction between metaphor, metonymy, and narrative as social practices by analyzing two samples of printed and internet advertisements, which are selected according to variations in time, genre, and mode.

- The realization and nature of implicit fictional narratives in printed and internet ads in English.

- The relation between the framing roles of multimodal metaphor and metonymy as well as the activation of story-lines in both genres.

- The local and global appeal of the advertisements, thus creating a tension.

- The role of the features of the fairy tale, the fantastic, the magic and wish worlds in ads.

- The influence of new technologies in literacy, together with the personalization and democratization processes that lead to the FRIENDSHIP metaphor that predominates in internet ads.

As a preliminary summary, we argue that advertising is a genre that occupies a central place in contemporary society and, as such, has been studied extensively by discourse analysts and metaphor theorists (see also COOK, 2001; SEMINO, 2008; URIOS-APARISI, 2009). However, little attention has been paid so far to the potential of metaphor and mental spaces in advertising discourse to evoke stories based on (global and local) sociocultural shared experiences and on the creative exploitation 
of (implicit) shared stories. In this paper, we discuss the relation between the framing roles of multimodal metaphor and mental spaces and the activation of story-lines in ads, as well as how this process supports a view of metaphor not only as a conceptual cognitive process, but also as a social and cultural practice. To achieve this, we analyze a selection of printed and internet advertisements from various English-speaking countries. In the case of printed advertisements, we focus on how fairy tales and stories of relationships, which possibly have universal influence, are evoked by metaphors. In the case of internet ads, we analyze a selection of ads of the same brand and their variations in various English-speaking cultures (India, the Netherlands, Australia) in order to discuss how local cultures adapt advertisements through the telling of local stories, some of which exploit well-known cultural stereotypes.

In addition, we analyze the relationship between multimodal metaphor and the features of the fairy tale, the fantastic, the magic and wish worlds in ads. Finally, we explore the distribution of source and target domains across the verbal, visual, and aural modes of metaphors in the analyzed ads and the conceptual processes of blending.

\section{Theoretical background}

The present study is framed theoretically within the current Conceptual Metaphor Theory (CMT) (LAKOFF \& JOHNSON, 1980; LAKOFF \& TURNER, 1989; JOHNSON, 1996; GIBBS, 2008) and within Blending Theory (FAUCONNIER AND TURNER, 1995, 2002; TURNER, 1996; DANCYGIER 2005), its applications to the study of discourse (see also CAMERON and LOW, 1999; CHARTERISBLACK, 2004; MUSSOLFF, 2006; SEMINO, 2008) and, in particular, of multimodal metaphor in advertising discourse (FORCEVILLE, 1996, 2009, 2012; URIOS-APARISI, 2009).

Our daily lives are saturated with narratives. From oral accounts of autobiographic episodes to literary fiction, including educational fables, narrativized lies, or accident reports, sequences of connected events stories - are constantly reorganized in contextually meaningful ways and turned into narratives, by altering chronological sequences for the effects of suspense, curiosity, and surprise (STERNBERG, 2001). From the CMT perspective, 'narrative is a fundamental mode of understanding, through which we make sense of all forms of human action [...]. Narrative is not just 
an explanatory device, but is actually constitutive of the way we experience things' (JOHNSON, 1993, p. 11). We adopt Johnson's (1993, p. 156) view that "both the order of narration and the principles of selectivity for relevant details are established within a culture" and that metaphor as a resource is "typically situated within the context of overarching narratives, which keep the episodes of our mundane existence from being isolated, unrelated events" (ibid., p. 170). In this sense, both metaphor and narrative play crucial roles in the framing and construction of coherence in discourse (see also Toolan, 2009; Forceville, 2013). In our understanding of the concept, coherence is a pragmatically-determined quality, requiring attention to the sense of the text in its sociocultural context. As Toolan (2009) points out, while metaphor provides lexical coherence, narrative provides structural coherence, and thus they complement each other. Within this process, repetition with variation and re-contextualization play central roles both in metaphorical and narrative realizations. This is manifested in multimodal discourse, such as that analyzed in this study, by the multiple multimodal cueing of meanings. With regard to the definition of multimodal metaphor, we follow Forceville (2009), who defines his phenomenon as follows:

...multimodal metaphors are metaphors whose target and source are each represented exclusively or predominantly in different modes. The qualification "exclusively or predominantly" is necessary because nonverbal metaphors often have targets and/or sources that are cued in more than one mode simultaneously (ibid, p. 24).

This definition is particularly insightful with regard to advertising discourse because, as shown by our data, we frequently find simultaneous cueing of both the source and target domains in both modes (see also Semino, 2008).

As regards the framing roles of metaphor and narrative in discourse, we wish to point out some important features regarding the nature of these discursive phenomena: first, frames do not exist in isolation, rather, they evoke and are linked to shared storylines and storytelling. Thus, a chosen frame foregrounds relevant aspects about an issue and hides what should be ignored (LAKOFF AND JOHNSON, 1980). Second, frames do not change greatly over time and across cultures and show a tendency to stay constant and unchallenged, in brief, they do not shift easily. Third, this stability of frames combines with the capacity and flexibility of advertising to adapt to 
and incorporate different discourse types, thus enabling the manipulation of pervasive collective frames by means of their activation. Framing is thus a resource to invoke implicit pragmatic meaning: by uttering a specific element, a narrative as a whole is invoked. This process of highlighting and hiding may additionally have ideological implications; therefore, the choice of one specific metaphor instead of another typically reveals the speaker/ writer's point of view or perspective. We will return to this dimension of the analysis below.

Furthermore, in our study, we analyze the role of metonymy and its interaction with metaphor. In metonymy, "a mapping occurs within a single domain, and [...] there is a "stand for" relationship" (LAKOFF AND JOHNSON, 1980, p. 36;). In this view, metonymy is "a conceptual projection whereby one experiential domain (the target) is partially understood in terms of another experiential domain (the source) included in the same common experiential domain" (BARCELONA, 2000, p. 4). It is also important to point out that the function of metonymy has a communicative and functional motivation, as argued by Forceville (2009b, p. 58) "A communicator's choice to use a specific metonym (the source concept) rather than the entity to which it metonymically refers (the target concept) always implies some change in salience or viewpoint." This leads Ruiz de Mendoza Ibáñez and Díez Velasco (2002, p. 496) to conclude that the main difference between metaphor and metonymy "concerns the domaininternal or domain-external nature of the mapping." We view the interaction of metonymy and metaphor as one in which metonymies motivate and articulate metaphors in discourse, often by means of metonymic chains that help create complex metaphorical meanings.

Finally, as explained in detail by Urios-Aparisi (2009) in his analysis of multimodal metaphor and metonymy in advertising discourse, in metonymy, the mapping of source and target typically involves the highlighting of one (sub)domain over another. Additionally, the target and source domains in a metaphor establish symmetrical correspondences between different concepts in a way that does not happen in metonymy, where these correspondences are set up in an asymmetrical manner.

With regard to the nature of the interaction between metaphor, metonymy, and narrative as social practices, we stress the importance of the function of metaphors and narratives as not only descriptive; metaphors and narratives do not merely represent fact or fiction, but also have a performative 
force and are 'invitations to action'. Actions can be, for example, 'buying a product', but they can also be 'emotional investment' and 'identity display' (NERLICH ET AL, 2009). Finally, narratives and metaphors interact dynamically by processes of re-contextualization of familiar scenarios in new contexts. Writers do not create new frames each time they deal with a topic, but rather use already existing ones in such a way that given words and expressions evoke whole storylines (see also Musolff, 2006; Semino, 2008; Nerlich et al., 2009).

Although we make use mostly of CMT and its application to the study of discourse to analyze our data, we use CI to study in detail an internet ad. We have chosen to apply this model in this particular case, because we believe it is a particularly rich advertisement which presents a complex interaction between various modes. Thus, we consider that the process of emerging metaphors and metonymies in relation to the narrative storyline is more adequately explained by the four-space model.

We follow Fauconnier and Turner's (1996, p. 113) view that mental spaces are "small conceptual packets constructed as we think and talk, for purposes of local understanding and action. They are interconnected, and can be modified as thought and discourse unfold." CI can be found in everyday language, as well as in other aspects of linguistic (e.g., advertising) and non- linguistic behavior (FAUCONNIER AND TURNER, 1995). In blending, the structure from two input spaces is projected to a separate space, the so-called "blend". The blend "inherits partial structure from the input spaces, and has emergent structure of its own" (FAUCONNIER AND TURNER, 1996, p. 113). Thus, "the power and even the existence of central inferences of the projection do not come from the source input space and from the target input space but only from the blended space" (Turner, 1996, p. 62). In Turner's (1996, p. 64) view "the blended space combines all the aspects of the storylines and we project partial structure from input stories and compose that structure in a blended story."

We consider CI particularly adequate for the explanation of how new meanings emerge in multimodal discourse, especially hybrid genres, such as the internet videos we analyze in the second part of our study. Thus, the four space model allows us to understand in greater detail the complexities of new metaphorical uses, since in addition to verbal and visual modes, aural and gestural modes are involved and CI provides an attempt to make sense of new domains of experience in new social situations. 
$\mathrm{CI}$ is also particularly adequate for the exploration of the creative re-contextualization of metaphor and narrative in advertising, because in blending, as in CMT, new meanings are seen as arising from already existing ones, often by means of metaphor clusters. "We frequently organize new material by extending a conventional category", in some cases provisional, in others permanent (FAUCONNIER \& TURNER, 2002, p. 269; see also Kövecses, 2010). In this process, it is important to remember that mappings in blends take place asymmetrically: in metaphor processes, 'input spaces do not have equal statuses as topics' (FAUCONNIER \& TURNER, 2002, p. 269), that is, in composing the blend, the source domain tends to have more prominence. Additionally, mappings are selective and only particular features from the input spaces are drawn upon to compose the blend.

With regard to the genre of advertising, we follow Cook (2001) in his view that advertisements play with the interaction of four worlds: The world of the sender, the fantasy world of the ad, the desired world of the addressee, and the real world of the addressee. The aim of the advertising company is to push the product via the fantasy worlds of the advertisement and the desired worlds of the addressee into the real world of the addressee. This view is particularly interesting for our analysis, which focuses on the interaction between metaphor and narrative in such a way that this dynamic process revolves around metaphors of TRANSFORMATION, MAGIC, FANTASY, and THE FAIRY TALE, which are typically manifested in the fantasy world of the ad and the desired world of the addressee. In advertisements, the product's selling point is constrained in time and space, and because of these restrictions, many aspects of the message are typically implicit. Thus, metaphor has a crucial place in the configuration of these implicit meanings.

With regard to the social dimension of advertising as a genre, it may be claimed that advertising reflects the essence of the social structure and cultural identity of a community, society, or specific culture. As such, metaphor is a resource for constructing identities in connection with sociocultural changes (KÖVECSES, 2005, 2010; ROMANO, 2013). Furthermore, metaphor is a fundamental means of expression of intersubjectivity, evaluation, and persuasion (COOK, 2001; SEMINO, 2008; HIDALGO-DOWNING \& KRALJEVIC MUJIC, 2013). It is worth pointing out that the persuasive pragmatic function of metaphor is often conveyed in a covert way. Metaphor thus performs an interpersonal function in which it is a resource for the organization of the interpersonal relations between the advertising 
company and the target audience, either to persuade them or to reinforce the company's own identity (e.g. corporate business identity). This function is closely related to the function of display, which has, as its main purpose, "to establish and maintain identity" differentiating that identity from others (COOK, 1992, p. 147). As argued by Cook (1992: 148), in advertising, "[w] e express our identity by accepting someone else's product, political program, sporting prowess or art, rather than by making our own."

To end this section on theoretical concepts, we wish to mention briefly some of the ideological implications of studying advertising discourse. However, we do not develop this dimension in detail since it is outside of the main scope of the present article.

Numerous scholars have emphasized the connection between discourse change and sociocultural change (FAIRCLOUGH, 1992; KOLLER, 2004). In particular, Fairclough (1992) points out that one of the major discursive tendencies in contemporary society is the "democratization, or removal of power asymmetries in discourse", together with informalization of discourse. At the same time, this democratization process can be argued to stress the globalization tendency of present-day media and communication, and the nature of creativity in contemporary society as involving the reuse and re-contextualization of familiar material in new contexts. This process of democratization and informalization has been observed in a previous study in which two samples of ICT advertisements from two time periods, 1999-2002 and 2010-2012, are compared (HIDALGO DOWNING \& KRALJEVIC MUJIC, 2013). This study shows a change in the way the relation between the ICT company and the potential customers is represented. Thus, while in the earlier period the ICT is typically represented metaphorically by means of GUIDE and POWERFUL ENTITY METAPHORS, which reveal an asymmetrical power relation between the ICT company and the customers, in the later period, the ICT company is represented in terms of the FRIENDSHIP metaphor, thus representing an equal power relation between the advertising company and the potential customer. Similarly, the process of informalization is observed in the scenarios and in the clothes worn by the entities in the ads. Thus, while the earlier period is characterized by the typical presence of businessmen dressed in suits, the second period shows a broader variety of scenarios, including natural settings and numerous representations of children and young people. 


\section{Methodology and data}

The data for the present study is a sample of advertisements from two different genres: three printed ads on global ICT products and services from English speaking business magazines, "The Economist" and "Newsweek". These data are from the period of the dot.com bubble burst (2000-2002); here, we focus on examining how fairy tales and stories of relationships are triggered by metaphor. These ads form part of a larger corpus of ads from the two time periods mentioned in section 2 above. The second sample of ads consists of three internet ads in English of the product Coca-Cola aimed at different cultural audiences. The internet ads are from youtube and date from 2001 to 2009. Our aim is to discuss how local cultures adapt advertisements through the telling of local stories, some of which exploit well-known cultural stereotypes. This selection of ads illustrates the tendency of advertising to produce a global projection while appealing to specific markets and audiences. The ads chosen in the present study have been selected ad hoc in order to illustrate the interaction between metaphor and narrative as good examples of how this process takes place in two different sub-genres, time periods, and different products in advertising. This study is thus qualitative in nature; a larger selection of ads would be needed to reach more general conclusions regarding the interaction between metaphor and narrative across time and sub-genres. For this purpose, we apply a qualitative analysis of the mechanisms of interaction between multimodal metaphor and metonymy and fictional storylines.

\section{Discussion}

\subsection{Three printed ads on global ICT products and services}

We explore in detail three examples of printed ads by focusing on the role of metaphor and metonymy, which act as narrative frame triggers in activating stories. The chosen examples are Infonet, Tellabs and LG ads. The three of them have the common feature that they evoke transformation processes, the first by using the frog-prince image and evoked story tale, the second and third by using the image of butterflies and caterpillars as images of transformation. The main difference between them is that the first and the second example represent US ICT companies (Infonet and Tellabs), while the third ad represents LG, the South Korean ICT company. 
Moreover, in the Infonet and LG ads, the representation of transformation moves from fantasy to more real world metaphor scenarios, whereas Tellabs, as we will see, is metaphorically representing an idealized biological process of metamorphosis representing the changes in the business world. Unfortunately, the printed ads cannot be reproduced, as we have not obtained permission to do so by the advertising companies.

The Infonet ad shows the image of a bright green frog with a king or prince's crown on its head, against a saturated red background. From the CMT perspective, we can identify the visual metonymy of A PRINCE'S CROWN STANDS FOR THE PRINCE, which evokes the "Frog Prince" story, a Western culture fairy tale creating the metaphor scenario of the transformation from frog to prince. This metaphorical scenario triggers the narrative of the prince being under a spell until he is kissed by a princess and thus recovers his original status as prince. The visual metonymy is reinforced by the metaphoric expressions in the ad's heading in example (1).

(1) Break the spell, communicate globally.

The first part of the heading (Break the spell) situates the reader in the realm of the fairy tale metaphor scenario, while the second part of the heading (communicate globally) connects the reader to the real world.

In the subheading of the ad (see example 2), the interaction between the fantasy world and the real world metaphor scenarios invites the target audience to participate in the magical transformation by using advertised products and services.

(2) Whatever you wish for your global communications, solutions from Infonet make it come true.

This process of evocation of the fairy tale by means of visual and verbal metonymies and metaphors is further reinforced by the following underlined and italicised linguistic metaphoric expressions, where we find the recurrent themes of the fairy tale, transformation, and wishes in example (3).

(3) As a multinational, your wish is for a seamless global network that delivers the full promise of your business systems investment. No need to wish. We make it happen every day. Global communications services for multinationals.

The metaphor scenario of magical transformation foregrounds the power of the advertised ICT company to change the consumer's needs, while the potential consumer is represented as the protagonist of the magical event. It is interesting to observe that the addresser activates a Western culture fairy 
tale theme of transformation but at the same time is aimed at multinational companies as stated twice in example (3).

The second example is an ad from Tellabs, where we can see a surprised business man who is observing the moment of a sudden biological transformation from a caterpillar to a butterfly. By means of two visual metonymies, BUSINESSMAN STANDS FOR POTENTIAL CONSUMER and METAMORPHOSIS OF BUTTERFLY STANDS FOR TRANSFORMATION OF ONE'S BUSINESS, and the metaphoric expressions in the heading of the ad (evolve, deliver, next-generation - see example 4). The addresser again evokes the narrative story of the transformation from caterpillar (negative evaluation of nontransformation, ugliness) to butterfly (positive evaluation of transformation, beauty, grace).

(4) Evolve existing networks to deliver next-generation services.

The visual metonymies and the heading project a positive storyworld that differs from the text given in the first paragraph (see example 5), which projects a negative storyworld. It evokes the story of a threat that business executives must face, because they are undergoing business changes caused by the appearance of the Internet.

(5) You face threats from agile new competitors combined with demands from the growth of the Internet. This requires you to think in new ways when it comes to meeting your customer's need. One of your greatest challenges is to migrate your current network to meet customer demands for next-generation services.

The narrative changes again in the following lines (examples 6 and 7) where the addresser offers the solution to the successful transformation of the target audience's business, metaphorically represented by the magical power of the company to transform the potential consumer's business to become a successful company.

(6) Tellabs' Clear Ideas will get you there.

(7) Today Tellabs brings you the vision, the creativity and the resources to make your transformation to tomorrow a success.

The representation of the advertised company with the magical power in examples (6) and (7) is further evoked by the conventional metaphor, FUTURE IS A DESIRED DESTINATION, which activates the BUSINESS IS A JOURNEY metaphor. In addition, this metaphor is viewed as the dual of the conventional metaphor, LIFE IS A JOURNEY (LAKOFF, 1993). JOURNEY metaphors are pervasive and deeply entrenched in Western thought 
and discourse (LAKOFF AND JOHNSON, 1980, LAKOFF, 1993; KOLLER, 2004; SEMINO, 2008). These metaphors are very productive in the area of new technologies and, in particular, for the internet and e-business (HIDALGO- DOWNING, KRALJEVIC MUJIC \& NÚNEEZPERUCHA, 2013).

With regard to evoking the storyworld of biological transformation processes and projecting them on business transformation, the addresser also relies on the deep-rooted analogy in Western thought between biological transformation and business transformation.

The third example is a full page spread of an LG ad in which we can see a hybrid, fantastic being, a woman with butterfly wings, and butterflies in the background activating the visual metonymies A WOMAN WITH BUTTERFLY WINGS STANDS FOR BUSINESS UNDERGOING TRANSFORMATION and BUTTERFLIES STAND FOR BUSINESSES TRANSFORMED TO A NEW WAY OF DOING BUSINESS. These are reinforced by the metaphoric expression in the heading; example (8) thus motivates the emergence of a MOTION metaphor. This metaphor combines with the JOURNEY metaphor in example (9), referring to the journey between the fantasy world and the real world. In example (10), the addresser projects a positive storyworld of business transformation which is made possible because of the power of the advertised company in digital technology. The advertised products are placed below, representing the real world of the reader.

(8) Life in full swing.

(9) There is often a fine line between dream and reality. One step and you're in a different world. Dreams are individual and everyone has their own. Some realize theirs, others don't. To make something possible, which until now seemed impossible, is an ambitious goal.

(10) But no matter what you desire, be it consumer electronics, communication systems, or home appliances, we can help. With digital technology from LG.

The theme of transformation and magic in the printed ads analyzed so far seems to represent the ICT company in a powerful position, which enables it to solve the difficulties or problems of potential clients as if by magic. The presence of animals that undergo transformations is characteristic of these ads, and indeed animals are used frequently in advertising discourse to create metaphors. In the case of the analyzed ads, it can be argued that the asymmetrical power relation between the ICT company and the potential consumer is reflected in the choice of the animals: the would-be-prince frog 
is the potential consumer, while the entity who has the power to transform this state is the ICT company. Similarly, in the other two printed ads, the potential client is associated with the status of caterpillar or hybrid being, thus being represented as not fully developed and contrasting to the butterfly, which represents the powerful company. In the following section, we will observe differences between the internet ads and the analyzed printed ads, both with regard to the relation between metaphor and narrative and the power relations between ICT company and potential consumer.

\subsection{Three internet ads}

We will now examine in detail three examples of internet ads aimed at audiences from different cultures. For this purpose, we have selected three Coca-Cola ads found in youtube videos. This selection of ads illustrates the tendency of advertising to have a global projection while also appealing to specific markets and audiences. In these ads, we find the exploitation of fantasy and magic (the magical world inside the Coca-Cola machine and the stereotyped but fantastic cultural variations).

The first Coca-Cola ad was produced in The Netherlands. The second Coca-Cola ad was made in Australia, and the third was made in India. According to the storyworld projection in each of these, the first two ads are aimed at a Western culture audience, while the third ad targets mainly an Indian audience. The metaphor scenarios and the storylines of the first two ads will be analyzed from the CMT perspective and the cross domain mapping, while the last Coca-Cola ad will be analyzed from the perspective of CI, which is rooted in the CMT. Our analysis focuses on the role of metaphor and metonymy in the first two ads and on the role of mental spaces in the last ad. We argue that in these ads, unlike the printed ads discussed above, the metaphors and mental spaces perform a function of concluding and re-interpreting the initial narrative frame as the story develops. Thus, while in the printed ads the metaphor and metonymy interaction triggers the narrative frame, in the internet ads it is the narrative that leads to a concluding metaphor, which typically involves a re-interpretation of the story. The first ad connects with the previous theme of the relation between fantasy/fairy tales and the real world, whereas the second and the third ads show a recontextualization of the product in two different cultures - Australia and India.

The first example is a 1.32-minute-long Coca-Cola ad with the title "Fairy tale in a vending machine." This ad was produced in The Netherlands 
in 2006. Multimodal metaphors in this ad are based on the interaction of visual and aural triggers. There are no verbal forms of expression in the construction of meaning, and the music is particularly important (see also Alonso, Molina, and Porto, 2012).

In the first scene, we can see the real world framing of the storyline. It is an everyday scene of a young man who wants to buy a bottle of Coca-Cola from a street vending machine. He inserts a coin in the vending machine. When the coin is inside the vending machine, it reaches the fantasy world where the bottle will be filled with the advertised product. At that moment, the music of Coca-Cola starts. The following scenes provide a fairy tale storyline framing and the development of a fantasy world inside the machine. The same music accompanies the coin in its journey through the fantasy world and during the magic production of Coca-Cola.

In the final scene of the ad, the bottle of Coca-Cola comes out of the vending machine and brings us back to the real world frame. The young man collects the product. There is a pause in which he looks at the bottle. When he opens it, the music of Coca-Cola starts again. This implies the assumed reception of the additional value of the product. It is not just any drink but something special, magical.

We can identify two narrative frames in this ad: the external, the real world(s) of the consumer/character in the ad, and the internal, the fairy tale world of the product. The two narrative frames fuse when the ad's protagonist opens the bottle, and the music from the magic world enters the real world. Music thus creates the connection between the two narratives into one story, implying that the protagonist forms part of the fairy tale metaphor scenario and of the "real world" at the same time. From an ideological perspective, this fusion may be interpreted as a more symmetrical power relation between company and consumer: the company enables or facilitates the transformation, again, as if by magic, but the represented consumer is not aware of how the transformation has taken place.

As regards the metaphor scenario, this is first manifested by the metonymy COIN IN THE VENDING MACHINE STANDS FOR THE BUYING TRANSACTION and the JOURNEY metaphors which play an important role in the ad. On the other hand, the JOURNEY metaphor invokes the SOURCE-PATHGOAL image schema, the movement towards a destination. As is well-known, image schemas structure both our bodily experience and our non-bodily experience by means of metaphor (LAKOFF, 1987; JOHNSON, 1987; 
CLAUSNER AND CROFT, 1999). Following Johnson (1993, p. 169) the basic mapping exists "between the three domains of spatial movement, journeying, and story structure, based on the underlying SOURCE-PATH-GOAL schema [...] The SOURCE-PATH-GOAL schema is thus the basis for our sense of stories as both literal or figurative journeys." Johnson further argues that there is a STORY IS A JOURNEY metaphor. In our example, it becomes the STORY OF COCA-COLA PRODUCTION IS A MAGIC JOURNEY metaphor, which represents the creative re-contextualization of the conventional metaphor (HIDALGO-DOWNING \& KRALJEVIC MUJIC, 2013). This motivates the metaphorical interpretation of co-occurring images and music, such as the fantastic creatures inside the vending machine or the music coming out of the Coca-Cola bottle, thus creating patterns of the extended metaphor COCA-COLA IS A MAGIC POTION. To sum up, the metaphor emerges through the development of the two storylines, the narrative lines lead to the metaphor, but the represented consumer is unaware of the MAGIC POTION metaphor, he simply feels something has changed.

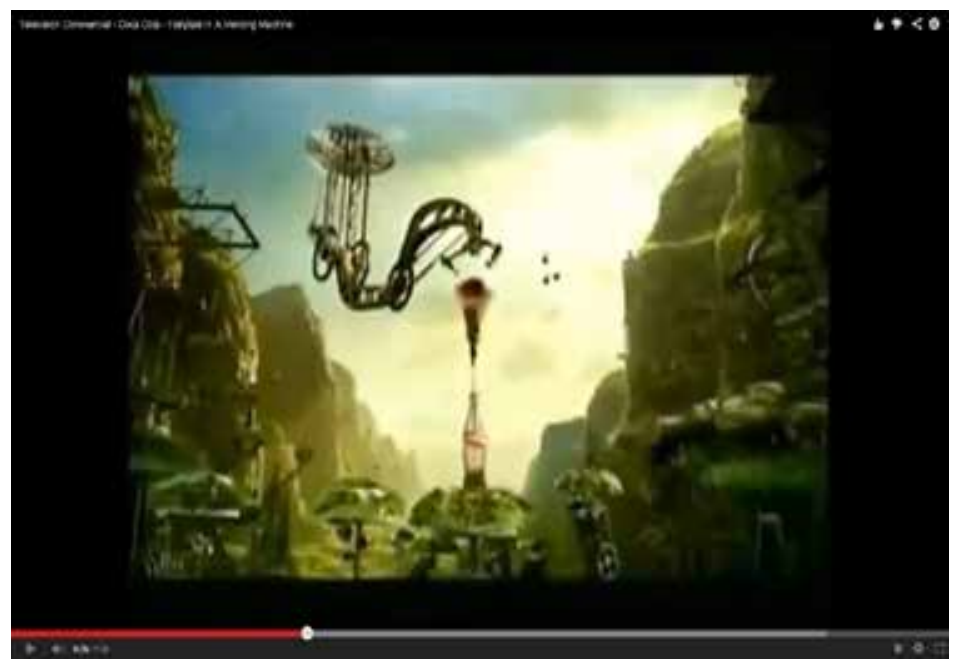

Figure 1: Coca-Cola ad: Fairy tale in a vending machine

The next example is a one-minute-long Coca-Cola ad with the title "Australian summer commercial, open happiness", produced in Australia in 2009 as part of the Coca-Cola 'happiness in a bottle' campaign. In the opening scene, we can see the sun and the blue sky, followed by an image of two young people lying on the beach, representing an Australian stereotype 
of youth. In the following scenes, more young people run towards the beach. They are swimming to a floating artifact and then floating inside it. The Coca-Cola music accompanies the activity. It is a song by Butch Walker et al., with some interesting linguistic expressions in the song. We can hear the expression "lift me up" (example 11) next to the expression "I was down" in example (12). These metaphoric expressions evoke the HAPPY IS UP and SAD IS DOWN orientational metaphors as "drooping posture typically goes along with sadness and depression, erect posture with a positive emotional state" (LAKOFF \& JOHNSON, 1980, p. 15):

(11) C'mon lift me up (it's a brand new day)

(12) Just think yesterday I was down and out

Similarly, the adverb "out" in example (12) can be related to the negative emotional state which contrasts with the image of happy young people floating inside the artifact. However, when the voice-off sings "Happiness overflowing" (example (13), this metaphoric expression reinforces the visual mode by representing the young people flying out of the bottle.

(13) Today I woke feeling lovely,

Happiness overflowing knowing somebody loves me.

The young people open bottles of Coca-Cola, while they hold hands and smile, thus creating the sense of community. The image of the overflowing liquid also has a sexual connotation as part of the enjoyment and happiness. This is reinforced by the phallic shape of the bottle and by the implied metaphor overflowing COCA-COLA IS AN ORGASM and SEX IS UP, SEXUAL SATISFACTION IS IN as extensions of the HAPPINESS and the UP and IN/ OUT metaphors. Example (14) is a chorus which accompanies the images of young people while they are opening Coca-Cola bottles.

(14) Open up some happiness

In the final scenes, the audience can see that the artifact is a huge floating plastic Coca-Cola bottle and the manifestation of the COCA-COLA IS THE CONTAINER OF HAPPINESS metaphor and COCA-COLA IS THE CONTAINER OF SEXUAL SATISFACTION metaphor. 


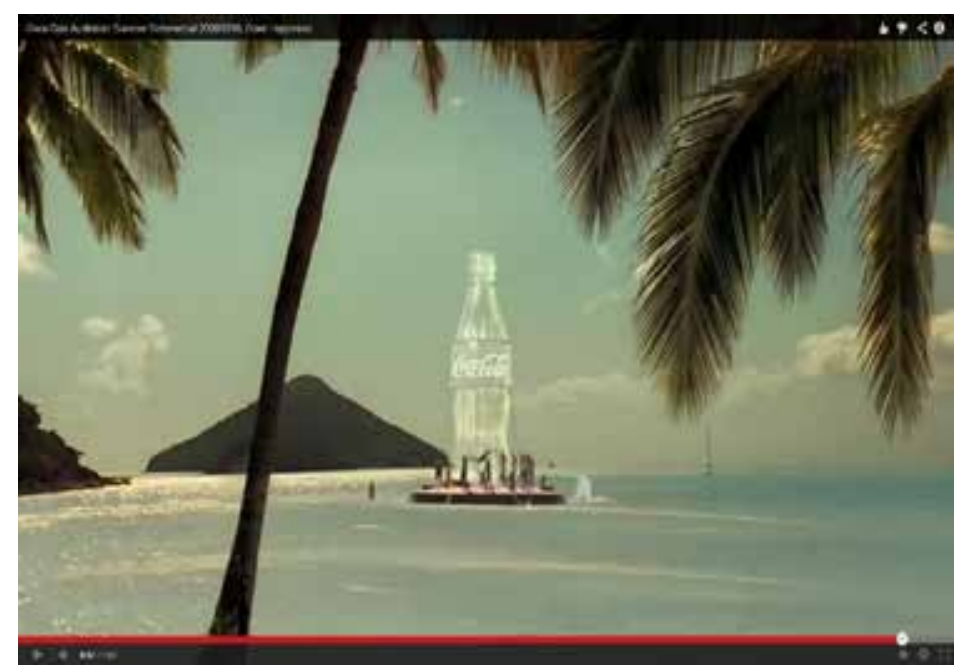

Figure 2: Coca-Cola ad: Summer commercial: Open Happiness

With regard to the storyworld projection in this ad, we can argue that since the bottle cannot be seen as such at the beginning of the ad, and, furthermore, it is empty, that is, it is the young people who open CocaCola bottles inside the floating artifact, the audience has to reinterpret the narrative. Thus, the initial narrative which shows young people enjoying themselves on the beach on an indeterminate floating artifact, is reinterpreted as a narrative where the Coca-Cola drink is the facilitator of this enjoyment and happiness. From an ideological point of view, however, it invites the critical reader to perceive a stereotyped and trivialized representation of youth, interested in enjoyment and sexual pleasure.

As our examples show, ads try to combine both global and local needs, grounding the global theme in specific cultural experiences, which are evoked by multimodal means. In this Coca-Cola ad, the global themes of happiness, youth, and entertainment are re-contextualized in the Australian cultural context of the life on the beach, thus aimed at the target culture. This may be argued to illustrate the processes of democratization and informalization mentioned in the theoretical review above.

Our last example is a one-minute-long Coca-Cola ad with the title "Classic Indian Commercials-Coke AD", which appeared on YouTube in 2010, although the advertised company stopped showing it on Indian TV in 2002 (Business Line, 19 December 2002). The opening scenes show the real 
world frame of a music recording studio with two children who are looking through a door into the studio. The storyworld projects a public frame. This is made explicit by the sign: ON AIR. When the children enter the studio unnoticed, the Coca-Cola music starts. They open bottles of the advertised product and start playing the Coca-Cola music with the instruments. The music is combined with the sound of the Coca-Cola drinking. The face of Aishwarya Rai, a famous Indian actress appears, and the spectator has to revise the studio framing, as it shifts from the public to the private frame. We can see that she is in her own apartment listening to the music. In the meantime, both she and the children are drinking Coca-Cola.

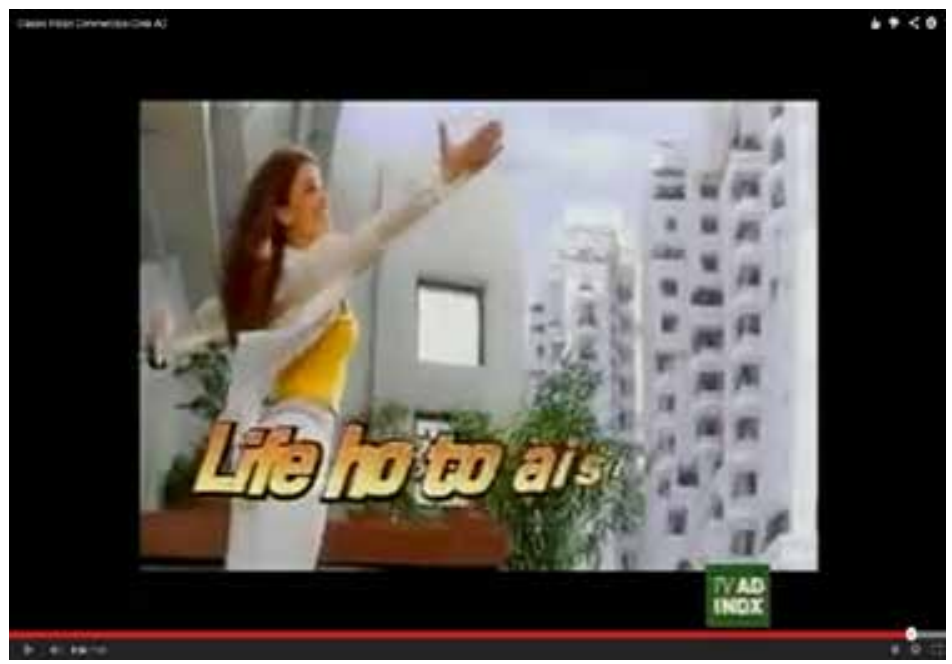

Figure 3: Coca-Cola ad: Classic Indian Commercials-Coke ad

In this ad the multimodal narrative is based on the interaction of visual, musical, verbal, and movement features. The musical sequence in particular accompanies the narration, while the children do the rhythm and the actress starts dancing with the Coca-Cola melody. The characters in this story do not use verbal forms of communication between them. Only a chorus repeats (example 15) the ad's slogan which can be translated into English as "Coca-Cola, That's what life should be like!" This expression evokes the title of a Bollywood (2005) film "Vaah! Life Ho Toh Aisi!".

(15) Coca-Cola,

Life ho to aisi! 
This example shows a narrative development from the individual and private to the community sharing, which is reinforced by the fact that the actress's agents try to intervene in the situation, but they finally let the interaction with the children and the crowd standing outside the actress's flat happen, so that magic and the unexpected can take place. The interaction between these features leads to the dynamic projection of an identity represented in the fantasy world of the receiver. The ad invites the receiver to identify herself with this fantasy world and bring it into his/her real world.

Here, we will analyze this ad using the CI perspective. Here is an explanation of a simplified version of that diagram (see Figure 4). The processes are represented as follows. The generic space at the top of the diagram represents the pre-existing similarity between target and source, or input spaces 1 and 2, which are situated on the left and on the right. These two "mental spaces" bring salient factual, emotive, and/or associated information to the blend. This can be achieved because the characters in our example, children and the actress in the input spaces, share a specific significant feature - they are drinking Coca-Cola. There are certain salient aspects which are not shared between the input spaces in our example between the actress and the children. However, both the shared and unshared salient characteristics are necessary for the blended space (see also Fauconnier and Turner, 2002; Forceville, 2012). Following Fauconnier and Turner (2002, p. 42) "the blend develops emergent structure that is not in the inputs," while Turner (1996, p. 59) argues that "specific information from source and target is projected into the blended space."

In our example, what is shared in both input spaces by the characters is the consumption of the advertised product. In addition, the "resulting whole" can be seen as creative, as it is more than the sum of the parts (FORCEVILLE, 2012, p. 117-18). The arrows in the diagram represent properties which connect the generic space with the input spaces and the blend. Since properties between the input spaces are not relevant for the blend, we have not connected them with an arrow. However, the arrows connect each input space with the blend, thus representing the properties created by the combination of the input spaces, which subsequently signify the new, "emergent properties" (FORCEVILLE, 2012, p. 118).

We analyze this example from the CI perspective since the CTM mapping from the source to the target could not bring the new emergent properties that only appear in the blended space. 


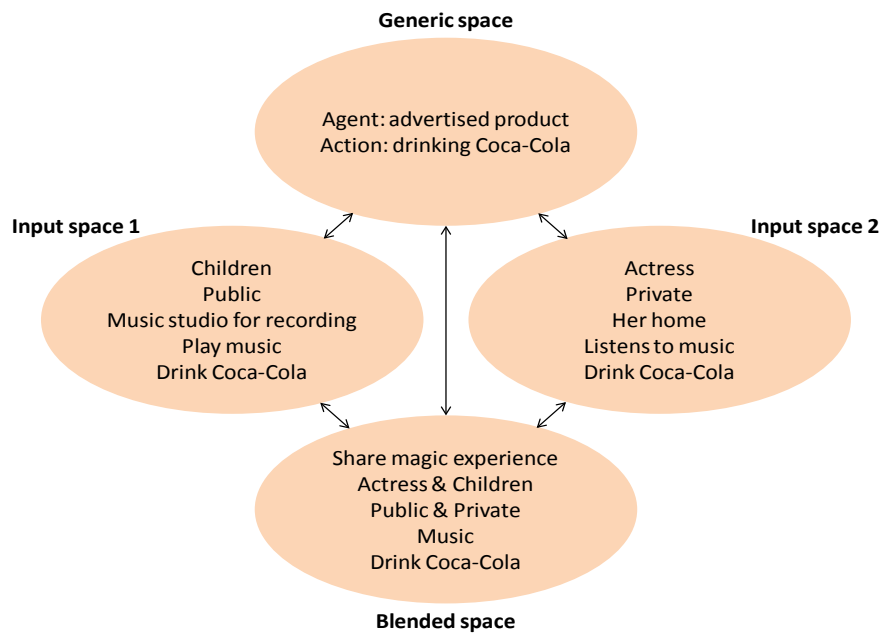

Figure 4: Blend of Coca-Cola India ad

In other words, magic cannot be projected directly from the source to the target, because it does not exist in the source. Instead, it emerges in a blended space and is then projected onto the target. This may be interpreted by making reference to the ideological implications of the choices made in the narrative development as well as in the input spaces and emergent domains in the blend. Thus, the transition from private to public domains, from individual singing, dancing, and drinking Coca-Cola to the community sharing of this event when the actress comes out to the balcony and is accompanied by a chorus of numerous people singing, dancing. and drinking Coca-Cola, indicating that there is complicity between them and the actress. The advertisement thus projects the illusion that people can not only share some minutes with the famous actress, but can share her identity, singing and dancing with her. In this process, it is the drink again, CocaCola, and the accompanying music, that are the facilitators and enablers of this 'magical' fusion of identities. In terms of Fairclough's (1992) categories of democratization and informalization, we can observe that they are again present in this ad, in which the life of a top star is presented as accessible to everybody. 


\section{Conclusions}

In the present article, we have discussed how the interaction between metaphor-metonymy and narrative in advertising can be considered a social practice, in the sense that it provides a clear example of how social changes take place in time and across genres and cultures, and are represented and re-contextualized creatively in discourse. Indeed, we have stressed the importance of metaphor, metonymy, and narrative as social practices and not only as 'ways of thinking' or 'telling'; they constitute instruments of persuasion and display with ideological implications. We have paid special attention to the analysis of the interaction between multimodal metaphor and narrative, a topic which has not received sufficient attention so far. We have also argued that ads try to combine both global and local needs, grounding the global theme in specific cultural experiences, which are evoked multimodally. The themes may be universal or traditional stories of transformation, such as the frog that turns into a prince and the caterpillar into a butterfly. The fairy tale genre is exploited often to evoke explicitly or implicitly alternative storylines which give the ad an additional meaning based on MAGIC and FANTASY metaphors. Metaphor and metonymy thus play a crucial role in the structuring of fictional storylines and the (re) interpretation of the ad. The role of these features is performative and invites consumers not only to buy the product, but also to engage in a projected identity. The similarity we have identified between the printed and the internet ads is that both genres use metonymy to evoke and activate the metaphors and the narratives. The main difference we have observed is that, in the printed ads, the metaphor triggers the narrative storyline, while in the video ads, narrative leads to the metaphorical (re-)interpretation of the story.

In the Coca-Cola ads the global themes of happiness and entertainment are re-contextualized in various cultural contexts, depending on the target audience. In the internet ads, the aural mode, specifically the music, plays a crucial role in the structuring of the metaphorical and narrative frames. This is most evident in the Indian Coca-Cola ad, which we analyze by applying CI in order to show that the emergent space is articulated by the music and connected to the 'magic' attribute of the product, which is not present in the input spaces.

Finally, we have pointed out that a tendency in social practices in advertising genres, from printed ICT ads to internet ads of Coca-Cola, seem to show the ongoing transition of the process of democratization and informalization discussed by Fairclough (1992) as part of discourse and social 
change. In the present study, it may be argued that both the differences in the advertised products (ICTs and Coca-Cola) and the sub-genres (printed ads from 2000-2002 and internet ads from 2001-2009), show that the relation between the advertising company and the potential consumer is represented in different ways. Thus, a subtle change can be observed in the power relations between advertising company and consumer manifested in the printed ads of the earlier period as an asymmetrical power relation in which the advertising company is a guide and a powerful entity, while in the internet ads the relation between advertising company and consumer is based on a symmetrical power relation based on a FRIENDSHIP metaphor, which facilitates the creation of happiness. In both cases, the advertising company is the facilitator or enabler of a 'magic transformation' in the potential consumer.

As further food for thought, we wish to stress the need to explore in greater detail the interaction between different modes, as in internet ads where the verbal mode loses prominence, and the other, where more sensorial modes (visual, sound, movement) and the global nature of new technologies gain weight and have a more immediate impact. Similarly, it may be worth exploring the ideological implications of the analysis of advertising as a conservative social practice, which makes use of and promotes stereotypes that can easily reach a broad audience, both in local and international domains. From an ideological perspective, this implies that a critical analysis of advertising as a discourse practice shows that certain brands, like CocaCola, which we have analyzed here, cleverly make use of these possibly frivolous, unrealistic, and superficial stereotypes to reach broad audiences by exploiting the FRIENDSHIP and other related metaphors.

\section{Acknowledgements}

The results of the present study are part of three broader research projects, the first financed by the Spanish Ministry of Science and Innovation (Ref. FFI2008-01471), entitled 'Language variation and intercultural communication: A discourse-pragmatic approach to intersubjectivity, identity construction and creativity in English Discourse'; the second financed by the Spanish Ministry of Competitivity (Ref. FFI2012-3790), entitled 'Analysis of Persuasive Communicative Discourse Strategies in English and Spanish: Socio-Cognitive and Functional Interactions'; the third financed by UAM-BSCH, entitled 'Language and Creativity across modes 
and cultures' (2013-2014). We are very grateful to Coca-Cola for allowing us to reproduce screen shots from three internet advertisements of the company.

\section{References}

ALONSO, I.; MOLINA, S.; PORTO REQUEJO, D. Multimodal digital storytelling: Integrating information, emotion and social cognition. Review of Cognitive Linguistics. Special Issue on Multimodality and Cognitive Linguistics. v. 11, n 2, p. 369-387, 2012.

BARCELONA, A. (Ed.). Metaphor and metonymy at the crossroads: A cognitive perspective. Berlin \& New York: Mouton de Gruyter, 2000.

CAMERON, L. \& LOW, G. D. (Eds.). Researching and applying metaphor. Cambridge: Cambridge University Press, 1999, 295 p.

CHARTERIS-BLACK, J. Corpus approaches to critical metaphor analysis. New York: Palgrave MacMillan, 2004, 280 p.

CLAUSNER, T.C.; W. CROFT. Domains and image-schemas. Cognitive Linguistics, v. 10, n. 1, p. 1-31, 1999.

COOK, G. The Discourse of Advertising. London: Routledge. 1992. 250 p.

DANCYGIER, B. Blending and narrative viewpoint: Jonathan Raban's travels through mental spaces. Language and Literature. v. 14, n. 2, p. 99-127, 2005.

FAIRCLOUGH, N. Discourse and Social Change. Cambridge: Polity Press, 1992, $259 \mathrm{p}$.

FAUCONNIER, G.; TURNER, M. Blending as a central process of grammar. In: GOLDBERG, A. (Ed.). Conceptual Structure, Discourse, and Language. Stanford: Center for the Study of Language and Information. 1996, p 113-130.

FAUCONNIER, G.; TURNER, M. Conceptual integration networks. Cognitive Science. v. 22, 1998, p. 133-87.

FAUCONNIER, G.; TURNER, M. The way We Think: Conceptual Blending and the Mind's Hidden Complexities. New York: Basic Books, 2002, 464 p.

FORCEVILLE, C. Pictorial metaphor in advertising. London: Routledge, 1996, $233 \mathrm{p}$.

FORCEVILLE, C. Non-verbal and multimodal metaphor in a cognitivist framework: Agendas for research. In: FORCEVILLE, C.; URIOS-APARISI, E. (Eds.). Multimodal metaphor. Berlin \& New York: Mouton de Gruyter, 2009a, p.19-42.

FORCEVILLE, C. Metonymy in visual and audio visual discourse. In: VENTOLA, E. and MOYA, A.J. (Eds.). The World Told and the World Shown: Multisemiotic Issues. London: Palgrave Macmillan, 2009b. p. 56-74. 
FORCEVILLE, C. Creativity in pictorial and multimodal advertising metaphors. In: JONES, R.H. (Ed.) Discourse and creativity. Harlow: Pearson, 2012, p. 113-132. FORCEVILLE, C.; RENCKENS, T. The GOOD IS LIGHT and BAD IS DARK metaphor in feature films. Metaphor in the Social World. Special Issue on Metaphorical Creativity Across Modes. v. 3, n. 2, p. 160-179, 2013.

GIBBS, R. W. Researching metaphor. In: CAMERON, L.; LOW G. D. (Eds.), Researching and applying metaphor. Cambridge: Cambridge University Press, 1999. p 29-47.

GIBBS, R.W. Jr. (Ed.). The Cambridge Handbook of metaphor and Thought. Cambridge: Cambridge University Press, 2008.

HIDALGO-DOWNING H.; KRALJEVIC MUJIC, K. B. (Eds.). Metaphor in the Social World. Special Issue on Metaphorical Creativity Across Modes. v. 3, n. 2, 2013. HIDALGO-DOWNING, H.; L., KRALJEVIC MUJIC, K. B.; NÚNEEZPERUCHA, B. Metaphorical creativity and recontextualization in multimodal advertisements on e-business across time. Metaphor in the Social World. Special Issue on Metaphorical Creativity Across Modes. v. 3, n. 2, p. 199-219, 2013.

JOHNSON, M. Moral Imagination. Implications of Cognitive Science for Ethics. Chicago: Chicago University Press, 1993. 302 p.

KOLLER, V. Metaphor and gender in business media discourse: A critical cognitive study. Basingstoke: Palgrave Macmillan, 2004. 244 p.

KÖVECSES, Z. Metaphor: A practical introduction. Oxford: Oxford University Press, 2002. $304 \mathrm{p}$.

KÖVECSES, Z. Metaphor in culture: Universality and variation. Cambridge: Cambridge University Press, 2005. 314 p.

KÖVECSES, Z. A new look at metaphorical creativity in cognitive linguistics. Cognitive Linguistics, vol. 21, 2010. p. 663-697.

LAKOFF, G.; JOHNSON, M. Metaphors we live by. Chicago: University of Chicago Press, 1980. 256 p.

LAKOFF G.; TURNER, M. More than cool reason: A field guide to poetic metaphor. Chicago: University of Chicago Press, 1989. 237 p.

MUSOLFF, A. Metaphor scenarios in public discourse. Metaphor and symbol vol. 21, 2006. p 23-38.

MUSOLFF, A.; ZINKEN, J. (Eds.). Metaphor and Discourse. Palgrave: MacMillan, 2009. 269 p.

NERLICH, B.; ELLIOTT R.; LARSON, B. Communicating Biological Sciences. Ethical and Metaphorical Dimensions. Farnham and Burlington: Ashgate, 2009. $266 \mathrm{p}$. 
ROMANO, M. Situated-'instant' metaphors: Creativity in Spanish 15M slogans. Metaphor in the Social World. Special Issue on Metaphorical Creativity Across Modes, vol 3, n. 2, p. 240-259, 2013.

RUIZ DE MENDOZA IBÁÑEZ, F. J.; DÍEZ VELASCO, O. I. Patterns of conceptual interaction. In: Dirven, R. and Pörings, R. (Eds.). Metaphor and Metonymy in Comparison and Contrast. Berlin and New York: Mouton de Gruyter, 2002. p. 489-532. SEMINO, E. Metaphor in Discourse. Cambridge: Cambridge University Press, 2008. 247 p.

STERNBERG, M. How narrativity makes a difference. Narrative, vol. 19, n. 2., p. 115-122, 2001.

TOOLAN, M. Narrative Progression in the Short Story: First Steps in a Corpus Stylistic Approach. Amsterdam: John Benjamins, 2009. 212 p.

TURNER, M. The Literary Mind. New York/Oxford: Oxford University Press, 1996. 187 p.

TURNER, M.; FAUCONNIER, G. Conceptual integration and formal expression. Metaphor and Symbolic Activity, vol. 10, p. 183-204, 1995.

TURNER, M.; FAUCONNIER, G. Metaphor, Metonymy and Binding. 1998. Available at <www.wam.umd.edu/-mturn/www.metmet.html>. Accessed June 10, 2014.

URIOS-APARISI, E. Interaction of multimodal metaphor and metonymy in TV commercials: Four case studies. In: FORCEVILLE, C.; URIOSAPARISI, E. (Eds.). Multimodal metaphor. Berlin \& New York: Mouton de Gruyter, 2009. p. 95-118.

\section{Sources}

The Hindu Business Line, 19 December 2002. Available at <http://www. thehindubusinessline.in/2002/12/19/stories/2002121902380600.htm>. Accessed July 22, 2014.

Coca-Cola ad. Fairy tale in a vending machine. Available at <https://www.youtube. $\mathrm{com} /$ watch?v=7kqomBb640A $>$. Accessed July 20, 2014.

Coca-Cola, Australia ad. Available at <https://www.youtube.com/ watch?v=nlpZRK2Yfd0>. Accessed July 20, 2014.

Coca-Cola, India ad. Available at <https://www.youtube.com/ watch? $=\mathrm{N} 2 \mathrm{muWKtHCnc \& feature=}=$ related $>$. Accessed July 20, 2014.

Data de submissão: 07/08/2014. Data de aprovação: 06/11/2014. 